\title{
CONVERGENCIAS FENOMENOLÓGICAS Y ARTICULACIONES CONCEPTUALES ENTRE LA ACEDIA EVAGRIANA Y LA CAÍDA HEIDEGGERIANA
}

\author{
Phenomenological convergence and conceptual articulations between the notion of \\ acedia in Evagrio and the notion of fall in Heidegger
}

Santiago Hernán Vázquez*

\section{Resumen}

En el marco de los estudios contemporáneos acerca de la noción de acedia, y de esta en la obra de su primer sistematizador, el monje filósofo Evagrio Póntico, el presente trabajo se propone, primero, mostrar las múltiples coincidencias entre las manifestaciones fenomenológicas de la acedia evagriana y las de la denominada "caída" del sistema heideggeriano. En el marco de las manifestaciones de esta última se consideran, entre otras, la avidez de novedades, las habladurías, la carencia de morada y otras, y se pone de manifiesto la tematización de idénticos fenómenos por parte de Evagrio Póntico en su conceptualización de la acedia. En segundo lugar, y avanzando ya en la condición vinculante de tales convergencias fenomenológicas, se analiza el rol que tiene la temática del cuidado de la muerte en la definición y configuración tanto de la acedia evagriana cuanto de la caída heidegerriana.

Palabras clave: Acedia, Caída, Heidegger, Evagrio Póntico, Muerte.

Abstract

In the frame of contemporary studies on the concept of acedia, and in the work of its first systematizer, the philosopher monk Evagrius Ponticus, this paper, firstly, proposes to show the many similarities between the phenomenological manifestations of acedia in Evagrius and those recognized as the "fall" in the Heidegger system. As part of the manifestations of the latter, the avidity of innovations, the gossip, the lack of lodging are considered; and we show the identical phenomena theming by Evagrius of Pontus in his conceptualization of acedia. Secondly, and moving into the binding capacity of such phenomenological convergences, we analyze the role of death care in the definition and configuration of both Evagrio's acedia and Heidegger's fall.

Key words: Acedia, Fall, Heidegger, Evagrio Póntico, Death.

\section{INTRODUCCIÓN}

El redescubrimiento de la obra de Evagrio Póntico y los estudios cada vez más abundantes acerca de su pensamiento, tienen en la profundización de la noción de acedia acaso su aporte más amplio y significativo. Póntico es, en efecto, el primer sistematizador de un concepto que constituye hoy una referencia ineludible en la historia de la psicopatología y del pensamiento filosófico en general.

Cara a la espiritualidad cristiana, la noción de acedia sigue, en la época patrística y a lo largo de la Edad Media, un itinerario semántico que desfigurará, en 
parte, el sentido evagriano original (Peretó Rivas, El itinerario, 37-46; Acedia, 9-16; Mutaciones, 167-173; Forthomme, De l'acédie, 95-244; Émergence, 23-34; Nabert, 9-12; Wenzel, Acedia, 73-102; The sin, 13-46; Guillaumont, Traité, 84-90). Constituyendo un hecho insistente que excede ciertamente el marco de la vida monástica que es aquel en el que se desarrolló inicialmente; la desaparición del término acedia operada en la modernidad (Forthomme, Émergence, 29; Peretó Rivas, Acedia, 13-15) no significará que la realidad o las realidades por él designadas dejen de ser objeto de reflexión por parte de escritores espirituales y de filósofos. Una reinvindicación parcial del término tendrá lugar hacia el siglo XIX en el marco de la literatura y de la mano fundamentalmente de escritores franceses como Charles Baudelaire ("Chercher le passage: "Vivre avec un être qui n'a pour vous que de l'aversion...». Le portrait de Sérène, par Sénèque. Celui de Stagire, par Saint Jean Chrysostome. L'acedia, maladie des moines. Le Taedium vitae" [18]1), Honoré Balzac ("C'est l'acedia du cloître, quelque chose d'aigri, de fermenté dans l'inoccupation croupissante des forces juvéniles, une tristesse vague et obscure." $[20]^{2}$ ) y Paul Bourget ("L'acedia monte, ce dégoût, cette tristesse des choses de Dieu qui donne au cénobite la nostalgie du siècle quitté, le désir d'une autre existence, une révolte intime et profonde, et c'est le Démon de midi" [9] $]^{3}$. Pero en la filosofia la palabra acedia no tendrá la misma suerte. Quizá las únicas excepciones sean Emmanuel Mounier, quien la menciona a modo de vicio imputable a los cristianos de su tiempo en su obra El afrontamiento cristiano ("[le christianisme] rejette la complaisance dans la souffrance comme il rejette la complaisance dans la culpabilité. Il a voit un retour de l'amour-propre et de la concupiscence de soi, une espèce de cette tristitia ou de cette acedia que tous les moralistes religieux depuis Cassien dénoncent comme un mal dévorant pénétré de péché" $\left.[80]^{4}\right)$; Walter Benjamin, que en su estudio acerca del drama barroco alemán la parangona a la melancolía y la presenta como un rasgo caracterológico de personajes literarios como Hamlet ${ }^{5}$; y Emil Cioran,

\footnotetext{
1 "Buscar el pasaje: «Vivir con un ser que solo tiene por vosotros aversión...». El retrato de Sérène, por Séneca. El de Estagirio, por San Juan Crisóstomo. La acedia, enfermedad de los monjes. El Taedium vitae" (Traducción mía. El subrayado es del autor).

2 "Es la acedia del monasterio, una cosa agria, fermentada en la desocupación estancada de las fuerzas juveniles, una tristeza vaga y obscura" (Traducción mía).

3 'La acedia aumenta, ese disgusto, esa tristeza de las cosas de Dios que da al cenobita la nostalgia del siglo dejado, el deseo de otra existencia, una rebelión íntima y profunda, este es el Demonio del mediodía" (Traducción mía. Subrayado del autor).

4 "[el cristianismo] rechaza la complacencia en el sufrimiento como rechaza la complacencia en la culpabilidad. Ve allí un retorno del amor propio y de la concupiscencia de sí, una especie de esa tristeza o de esa acedia que todos los moralistas religiosos después de Casiano denuncian como un mal devorador penetrado de pecado" (Traducción mía. Subrayado del autor).

5 "Pero es sin dudas pensable e incluso no improbable a la vista del pasaje de Albertinus, que con la masa inerte se esté aludiendo al concepto teológico propiamente hablando del melancólico, que se halla presente en uno de los pecados capitales. Se trata de la acidia, es decir, de la pereza del corazón (...) Si por lo demás la profunda mirada con que Rochus de Liliencron descifró la ascendencia saturnina así como algunas señales de la acidia en
} 
el que dedica vehementes y significativos párrafos a la acedia en por lo menos tres de sus obras ${ }^{6}$. El filósofo rumano menciona incluso a Evagrio Póntico y a San Nilo. Hoy se sabe que muchas de las obras atribuidas a San Nilo de Ancira son del mismo Evagrio y que fueron los copistas quienes, en razón del anatema caído sobre el Póntico, pusieron sus obras bajo otros nombres, principalmente el de San Nilo (Guillaumont, Traité, 31; Un philosophe, 84-87)

Pero hemos dicho que el eclipse del término acedia no significó que las realidades por él nominadas desaparecieran paralelamente de la consideración de los filósofos. En este contexto encontramos, por ej., las reflexiones acerca de la "desesperación de la debilidad" de Soren Kierkegaard que Josef Pieper ha parangonado con la acedia (Antología, 34) ${ }^{7}$; o las referencias de Nietzsche a la "profunda depresión, la pesada laxitud, la negra tristeza" (380), a las perturbaciones espirituales de toda clase que ocurren en los hesicastos del monte Athos (382), y que el filósofo de Sils María vincula causalmente a las demandas del ideal ascético, vinculación que, por lo demás, no escapó al mismo Evagrio Póntico, como hemos intentado demostrar en otro lugar (Vázquez, 11-13).

En esta línea encontramos también, y de modo eminente, a Martin Heidegger. Las convergencias temáticas y conceptuales, y las coincidencias en las descripciones fenomenológicas -traducidas a veces en equivalencias terminológicas- que se encuentran entre varios pasajes de Ser y tiempo y diversos aspectos del concepto de acedia, son abundantes, e incluso, por momentos, mutuamente complementarias.

Esta convergencia pregnante de planteos, temáticas y descripciones, ha sido, no obstante, escasamente registrada y poco desarrollada. El vértice principal de relación que se ha puesto de relieve tiene que ver, casi exclusivamente, con las

los rasgos de Hamlet no quiere verse privada de su mejor objeto, verá en este drama el espectáculo único de su superación dentro del espíritu cristiano" (En línea).

6 "A la sombra de los monasterios, una sorda tristeza hacía nacer en el alma de los monjes ese vacío que la Edad Media ha llamado acedía. Ese asco originado por el desierto del corazón y la petrificación del mundo es el tedio religioso. No un asco de Dios, sino un aburrimiento en Dios. La acedía son todas las tardes de domingo pasado en el pesado silencio de los monasterios" (Cioran, De lágrimas, en línea).

"Acedía. Este estancamiento de los órganos, este embotamiento de las facultades, esa sonrisa petrificada, ¿no te recuerdan a menudo el hastío de los claustros, los corazones desiertos de Dios, la sequedad y la idiotez de monjes execrándose en el arrebato extático de la masturbación? No eres más que un monje, sin hipótesis divinas y sin el orgullo del vicio solitario" (Cioran, Breviario, en línea).

"Su tensión [la del místico] se dirige fuera de sí misma o se mantiene tal cual en el interior de Dios, donde encuentra un apoyo y una justificación. Reducida a sí misma, sin la subyacencia de una realidad, sería dudosa o no intrigaría más que a la psicología. Admitamos, sin embargo, que esta realidad que la sostiene y transfigura sea ilusoria: en sus accesos de acedía, el místico conviene en ello. Pero tales son sus recursos, tal es el automatismo de su tensión que, en lugar de entregarse a lo indefinido y fundirse con ello, lo sustancializa, le presta su espesor y un rostro (...) Según Casiano, Evagrio y San Nilo, no hay demonio más temible que el de la acedía. El monje que sucumbe a ella será su presa hasta el fin de sus días. Pegado a la ventana, mirará hacia el exterior, esperará visitas, no importa cuáles, para charlar, para darse al olvido" (Cioran, La tentación, en línea).

${ }^{7}$ Hay, no obstante, una mención explícita del término acedia en la obra kierkegaardiana. Dicha mención se encuentra en la entrada del 20 de julio de 1839 del diario del filósofo danés (Kierkegaard, 293). 
consecuencias de la acedia enumeradas por Tomás de Aquino (322), y la caracterización heideggeriana de la cotidianidad del Dasein caído. Es aquí, en efecto, donde las equivalencias temáticas y terminológicas son más evidentes.

El primero en consignarlas ha sido Josef Pieper, quien en muchos lugares de su obra se ha ocupado del tema de la acedia. En dos marcos conceptuales distintos pero convergentes, aborda dicha noción el filósofo alemán: el de la esperanza y el del ocio contemplativo. En el primero la vinculación con Heidegger es señalada de modo explícito. Siguiendo la concepción tomista, Pieper identifica las filiae acediae de Santo Tomás con las características de la existencia cotidiana del pensamiento del autor de Ser y Tiempo (Pieper, Las virtudes, 290-292, 396), e incluso llega a agrupar a aquellas bajo una categoría heideggeriana denominada "posibilidades de abandonarse al mundo" (Pieper, Antología, 36). En el contexto de su reflexión acerca del ocio también aborda Pieper el tema de la acedia. No sin vehemencia impugna aquí la identificación de nuestro término con la pereza para el trabajo, y cifra precisamente en la laboriosidad febril, en el "trabajar y nada más que trabajar", y en la consiguiente ausencia de ocio contemplativo, una de las consecuencias actuales de la acedia (Pieper, Una teoría, 38; El ocio, 41-45). La mención de Heidegger no es explícita aquí, pero hecha aquella vinculación de la acedia con la existencia cotidiana del metafísico alemán, no resulta difícil adivinar en este trabajo desmesurado que aleja al hombre de sí, la misma realidad a la que se refiere Heidegger cuando habla de la tranquilización que se proporciona a sí el "Dasein caído" mediante el "ajetreo desenfrenado", que no por la quietud y la inactividad (Heidegger, Ser, 200).

Esta identificación entre trabajo desmesurado engendrado por la acedia al que se refiere Pieper, y el ajetreo desenfrenado de Heidegger, ha sido señalada por Kevin Aho (Aho, 226-227), quien se encuentra dentro de un grupo de autores que se ocupan del tratamiento pieperiano de la acedia mencionando, con énfasis diversos, las semejanzas con la existencia cotidiana o impropia de Heidegger. Aquí encontramos, a la par de Kevin Aho, a Bernard Schumacher (Schumacher, 534-536) y a Agustín Basave Fernández (361).

También el filósofo italiano Giorgio Agamben se ha referido brevemente a esta llamativa convergencia -que para él constituye una identidad lisa y llana- entre las manifestaciones de la acedia y la banalidad cotidiana de Heidegger, convergencia que, observa no sin asombro, "es incluso terminológica". Y aunque al inicio de su estudio cite a nuestro conocido San Nilo, su paralelismo se circunscribe a las filiae acediae del medievo (Agamben, 25-26). A la zaga del pensador italiano encontramos a Pintor Iranzo, quien para referirse a la relación entre la acedia y la "banalidad cotidiana" de Heidegger, con sus respectivas manifestaciones, utiliza los términos identidad y correspondencia (en línea).

Por último, la referencia más reciente la encontramos en un grupo de autores que abordan el paralelismo desde otro punto de vista, aunque siempre siendo la noción medieval de acedia -que no la patrística o evagriana- el término de relación. La categoría 
heideggeriana con la que se vincula aquí nuestro concepto es la de "disposición afectiva". En el marco de esta categoría, aparecen en conexión los conceptos de aburrimiento ${ }^{8}$ y tedio en tanto disposiciones afectivas fundamentales - parangonables a la acedia- que abren el propio Dasein y al ente completo. Michael Teunissen y, siguiendo a este, María Lucrecia Rovaletti y Martín Pallares sostienen que tales nociones heideggerianas continúan con la tradición de la acedia y profundizan y actualizan todas sus proyecciones teóricas. En efecto, la acedia - como el tedio heideggeriano- abre al ser de un modo peculiar y revela lo que el filósofo alemán llama el pesado carácter de la existencia, pues en esta se encuentra el peso del ser mismo. Heidegger confluye pues, según Tehunissen, con lo que indicó Santo Tomás cuando sostenía que la acedia arraigada en la sensualidad alcanza finalmente a dominar el entendimiento y su tedio característico, cuyo objeto propio es el bien divino, se extiende a todos los bienes (49-50). De esta manera la acedia, dirán heideggerianamente Rovaletti y Pallares, permite tanto la apertura ante nuestro poder-ser cuanto la caída en la impropiedad de nuestro ser (60).

Pues bien, siendo Evagrio Póntico quien conceptualiza por primera vez el término acedia recogiendo la herencia clásica que sobre él gravita, $\mathrm{y}$, por tanto, el que establece el punto de partida de los abordajes patrísticos y medievales posteriores, interesa -siguiendo la línea vinculante de los estudios citados-relacionar su concepción de la acedia con algunos aspectos del análisis existencial de Heidegger, a fin de observar semejanzas y verificar una posible complementariedad hermenéutica entre ambos abordajes. Por lo demás, la singular riqueza de la concepción evagriana que recoge la significación clásica del término, oscurecida en los abordajes posteriores, podría permitir que la vinculación, partiendo del evidente paralelismo entre las manifestaciones de la acedia y las de la caída heideggeriana, alcance terrenos inexplorados.

\section{LA ACEDIA EN EVAGRIO PÓNTICO Y LAS CARACTERÍSTICAS DEL MODO DE SER COTIDIANO DEL DASEIN}

Bernard Forthomme llama la atención acerca del hecho de que Evagrio Póntico utilice para referirse a una experiencia aparentemente reconducible a la melancolía -concepto que el monje filósofo conocía en su letra fina-, el término griego $\alpha ́ \kappa \eta \delta i ́ \alpha$, a la sazón poco usado y poco determinado (Forthomme, Émergence, 28). Rastreando los primeros usos de dicho término y su significación general (Forthomme, Émergence, 15-20; Peretó Rivas, Morir in solitudine, 177-178; Bouvier, 71; Vernant 105; Guillaumount, Traité, 85), y confrontando estos con la conceptualización que de él realiza Evagrio Póntico, se puede entrever la razón de su

\footnotetext{
${ }^{8}$ También Paul Gibbs en su libro "Heidegger's Contribution to the Understanding of Work-Based Studies" hace una breve referencia a la noción de acedia como antecedente de que él llama la concepción moderna de aburrimiento, concepción que tendría a Heidegger como su principal artífice: "The modern conception of boredom has an antecedent in the medieval concept of acedia, as one of the 'seven deadly sins' in the Christian tradition" (111). "La concepción moderna de aburrimiento tiene un antecedente en el concepto medieval de acedia, uno de los 'siete pecados capitales' en la tradición cristiana” [Traducción mía].
} 
elección: aquella experiencia de atonía, de dispersión y de disgusto generalizado e inespecífico que aqueja a los monjes $\mathrm{y}$, en general, a todo ser humano, es reconducible en sus causas a aquella actitud espiritual de descuido o huida de sí que, en sentido general y como lo explicitaremos más adelante, designaba el término

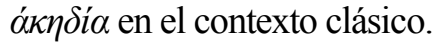

Tres son las obras donde Evagrio desarrolla principalmente su doctrina relativa a la acedia: el Tratado Práctico, el Antirrhético y Los ocho espiritus de la maldad. En dichas obras se pueden discernir dos niveles de aproximación: el uno la toma como sugestión demoníaca que actúa sobre un estado afectivo previo de atonía generalizada y que impulsa a abandonar el estado de vida. El otro la identifica más bien con dicha atonía y procura describir las características y efectos comportamentales de la misma, los que son, en virtud de una recíproca causalidad, los factores mismos que generan y refuerzan aquella atonía. Este segundo nivel de aproximación es el que está presente fundamentalmente en Los ocho espiritus de la maldad y el que registra un conjunto de fenómenos muy semejantes a los característicos de la "caída" heideggeriana. Ciertamente no solo en esta obra, pero sí principalmente en ella.

En primer lugar, destaquemos -pues es este hecho el que configura fenoménicamente ambos estados- que tanto la acedia como la caída se definen inicialmente como una huida, extrañamiento o alejamiento de sí. En la caída, en efecto, el Dasein vive alienado y lejos de sí, "se da la espalda a sí mismo" huyendo de sí hacia los entes intramundanos (Heidegger, Ser, 207) ${ }^{9}$. Por su parte, el monje acedioso de Evagrio es un fugitivo y un desertor que huye de sí al huir de la celda (Evagrio Póntico, Traité, 527; Guillaumont, Traité, 89). Resulta significativo que la huida que propone la acedia al monje sea hacia la casa paterna y hacia otros lugares en los que podrá dedicarse a oficios menos penosos. La razón principal que aduce el acedioso en su interior para consumar tal huida se resume en un axioma indeterminado pero tranquilizador: en todas partes la divinidad puede ser adorada (Evagrio Póntico, Traité, 525). Pues bien, el hacia-qué de la huida que consuma la "caída" heideggeriana es, también, hacia un presunto estar-en-casa tranquilizador que proporciona la publicidad cotidiana del llamado "Uno", esa instancia que aporta siempre una explicación que permita al Dasein permanecer tranquilo en su existencia impropia (Heidegger, Ser, 210-11).

La huida de sí se manifiesta, se concreta y se sostiene, en ambos casos, en conductas y en hábitos bien determinados. Heidegger enumera tres fenómenos principales: las habladurías, la curiosidad y la ambigüedad. Subsumidos a estos encontramos la distracción, la incapacidad de quedarse y la carencia de morada. En todos estos fenómenos asoma una estructura más originaria de la "caída" que Heidegger denomina "despeñamiento" y que está compuesta por la tentación, la

\footnotetext{
${ }^{9}$ Utilizaremos, en la mayoría de los casos, la traducción española a la obra de Heidegger “Sein und Zeit", hecha por Jorge Eduardo Rivera. A los fines de profundizar el análisis también se hará uso, en contadas ocasiones, de la traducción a la misma obra realizada por José Gaos.
} 
tranquilización, la alienación o extrañamiento de sí y el enredo en sí mismo (Ser, 189202). Las descripciones fenoménicas que en este punto realiza el filósofo alemán y las explicaciones que ensaya de tales fenómenos convergen e incluso, por momentos, podrían complementar las de Evagrio.

El monje acedioso se derrama en vagabundeos, curiosidades y murmuraciones (Peretó Rivas, La exclaustración, 29). Si bien el eremita evagriano es, por definición, un solitario, es decir, no tiene el contexto para desarrollar las habladurías, sí se llena de murmuraciones $y$ de un torrente de palabras que, como las habladurías heideggerianas, le obstruyen el acceso a la realidad y a él mismo (Evagrio Póntico, Contro, 129-142). El demonio que se identifica con la acedia "ha aprendido el lenguaje de los hombres" (Evagrio Póntico, Kephalaia, 151) y así produce su ataque en el lenguaje interior, llenando el pensamiento con palabras, creando una metarrealidad (Peretó Rivas, La exclaustración, 29; Palleschi, 67). Por lo demás, Heidegger puntualiza que la habladuría no se limita a la repetición oral sino que se propaga también como escribiduría y se alimenta de lo leído a la ligera $(\mathrm{Ser}, 191)$. Se trata de una condición que, más allá del hecho concreto de hablar, tiene que ver con una manipulación alienante de la palabra hablada, murmurada, leída o escuchada. El monje acedioso que murmura y se imagina conversaciones, también lee sin leer, cuenta las hojas, despliega las páginas, reprocha la escritura y la decoración (Evagrio Póntico, Gli otto, 57).

Aquella curiosidad -igualmente alienante- por la que el Dasein busca febrilmente lo nuevo como modo de disipación y evasión, sin profundizar en nada (Heidegger, Ser, 195), también es patente en el monje acedioso arrastrado por "la evasión fantástica", cuyo ojo está continuamente fijo a la ventana, espiando cuando siente voces, fantaseando sobre visitadores (Evagrio Póntico, Gli otto, 57). Como el monje pasa gran parte de su tiempo en el reposo contemplativo, la curiosidad evasiva propia de la acedia se manifiesta de modo idéntico a la del Dasein caído que está en reposo. Como ha dejado lo inmediatamente a la mano, el ver

tiende hacia el mundo distante y ajeno. El cuidado se convierte en búsqueda de las posibilidades de ver el mundo tan solo en su aspecto, reposando y demorando [junto a él]. El Dasein busca lo lejano solamente para acercárselo en su aspecto. El Dasein se deja llevar únicamente por el aspecto del mundo, y en este modo de ser procura deshacerse de sí mismo en cuanto estar-en-el-mundo (Heidegger, Ser, 195).

El monje acedioso, en efecto, se representa en su imaginación un nuevo oficio, un nuevo estado de vida (Evagrio Póntico, Traité, 525), ve en su fantasía otros lugares y se imagina construir allí una celda donde encontraría sin fatiga las cosas de las que tiene necesidad, el reposo y la consolación de los hermanos que vendrían hacia él, o se recrea imaginándose visitar su casa y a sus parientes por un poco de tiempo (Contro, 136-37).

La curiosidad heideggeriana tiene tres momentos constitutivos que se vienen insinuando ya en el monje acedioso de Evagrio. Primero, la incapacidad de quedarse en 
y ante las cosas buscando la excitación de lo siempre nuevo. Idéntica incapacidad presenta el monje evagriano: sus ojos están en constante movimiento, no medita demasiado tiempo en nada, está expectante por si algún hermano anda cerca, va de la ventana al muro y luego al libro el que no es para él objeto del "detenerse contemplativo" (Heidegger, Ser, 195), sino de una constante e inquieta manipulación que o calcula los fascículos o despliega las páginas o se detiene críticamente en la escritura y la decoración (Evagrio Póntico, Gli otto, 57). Heidegger nos dice que, en virtud de esta imposibilidad de quedar en y ante las cosas, el Dasein es incapaz del detenerse contemplativo. La acedia, por su parte, con su marcada tendencia al vagabundeo físico, sensitivo e imaginativo es el "principal adversario de la hesychía ['́rvxía]" (Guillaumont, Un philosophe, 200), término griego este último, intraducible al español que se vincula conceptualmente con la idea de ocio contemplativo, como bien nos indica Guillaumont (Un philosophe, 178), y que nomina, de acuerdo con Evagrio, la esencia de la vida monástica. Recordemos, por lo demás, aquello de Pieper, según ello la acedia sería - dirá el pensador alemán conservando un matiz de la noción patrística- la incapacidad del ocio contemplativo.

La distracción hacia nuevas posibilidades es lo que sigue, en el esquema heideggeriano, a una tal incapacidad. El espacio reducido de la celda y las pocas y siempre iguales actividades de la vida monástica limitan ciertamente el panorama estimular del monje y las posibilidades cotidianas de su existencia. Las cosas y actividades ante las cuales el monje no tiene la capacidad de detenerse y que se ofrecen como posibilidades de distracción se reducen a las pocas que conforman su universo: la Sagrada Escritura, algún manuscrito ocasional en su poder, la oración litúrgica semanal, la pared de su celda, la ventana si esta la tiene, la puerta, el oficio diario y-sobre todosu imaginación y sus recuerdos. Evagrio describe con detalle y sutileza, como venimos viendo, la manera en que estos pocos elementos del universo monacal sirven al propósito distractor y dispersante de la acedia. La lectura, la ventana, la puerta que chirria, los recuerdos de la familia, las imágenes de la ciudad, del rostro de algún hermano, ofrecen las posibilidades de distracción en las que el acedioso se derrama.

El último momento de la curiosidad del Dasein caído lo constituye la carencia de morada en virtud de la cual el existente heideggeriano se halla en todas partes y en ninguna. No mora ni reposa en lugar alguno (Ser, 195). De igual modo, "la oleada de la acedia saca al monje de su morada" (Evagrio, Gli otto, 57). Éste salta hacia fuera de la celda cuando la puerta chirria o espía constantemente por la ventana (Traité, 521; Gli otto, 57). Siente un tenaz deseo de salir a visitar a sus padres, parientes o amigos, o salir hacia la ciudad creyendo que allí encontrará morada (Contro, 136-141). Como señala Gabriel Bunge, el "estar sentado" en la celda, morada del monje, es la característica de la vida monástica, de tal modo que la expresión "estar sentado" se transforma en sinónimo de "ser monje" (Akèdia, 76). Pues bien, al anacoreta que sufre de acedia le resulta odioso permanecer sentado, y cualquier excusa es buena para saltar hacia la ventana o hacia fuera. La acedia, en efecto, es "el principal adversario de la hesychía 


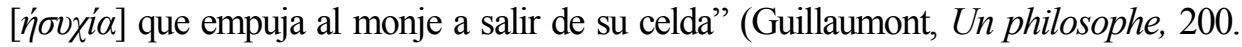
Trad. mía). El vagabundeo imaginativo y físico resulta para Evagrio un signo inequívoco de acedia que impele a consumar o consuma, de hecho, la huida definitiva hacia una situación ideal presuntamente mejor que solo profundiza la carencia de morada. Recordemos la utilización por parte de Evagrio de los términos fugitivo y desertor. Estos se aplican, primariamente, a la huida de la celda. Extrañado de sí, el monje no reposa en su alma, no tiene morada y huye buscándola. La celda que era su refugio y su residencia estable, está ahora "contaminada y llena de humedad y es el origen de todo género de enfermedades" (Contro, 134).

En este contexto, Evagrio utiliza un término revelador que la versión italiana de Ocho espiritus de la maldad traduce como girovago, el que, a su vez, procede del latín gÿrovagus, que quiere decir "sin residencia estable". Pero es el término griego usado por Evagrio el que posee una riqueza singular. Como sucede con la voz "acedia" ( $\alpha ́ \kappa \eta \delta i \alpha)$, el Póntico se apropia aquí de una palabra griega y le da una significación original que recogiendo el sentido originario del vocablo se proyecta en la designación de una conducta monacal no suficientemente especificada hasta allí. El término usado es, en efecto, $\kappa v \kappa \lambda \varepsilon v \tau \eta \dot{\zeta}$, el que deriva de los verbos $\kappa v \kappa \lambda \varepsilon v \dot{\omega} \omega$ у $\kappa v \kappa \lambda \varepsilon ́ \omega$, estos designan las acciones de rodear, envolver, mover en círculos, hacer dar vueltas, colocarse en torno de, dar vueltas, girar, transcurrir. Roelof van den Broek encuentra el equivalente inglés de nuestro término en el sustantivo "water-whell" (Van den Broek, Pseudo-Cyril, 21), literalmente "rueda hidráulica". El sentido sigue siendo el mismo: algo que gira y da vueltas. Evagrio justifica el uso adjetivante del término indicando, en efecto, que el monje poseedor de tal cualidad, como maraña del desierto, se detiene un poco y de nuevo, aunque no queriendo, recomienza a girar y

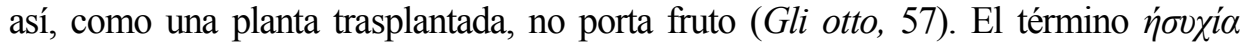
reaparece aquí como aquello que el monje giróvago apenas conoce. En efecto, vivir la

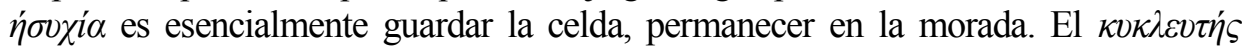

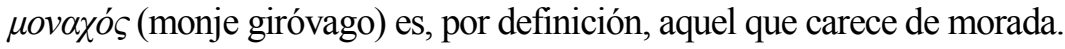

En la caída, el Dasein, nos dice Heidegger, se despeña o derrumba de sí mismo en sí mismo (Heidegger, Ser, 200; El ser, 206). Esta expresión utilizada por el metafísico alemán y que debe entenderse ciertamente en el marco de la condición premoral de su descripción de la existencia impropia, expresa, no obstante, con precisión, el drama del acedioso. Este consuma o se ve impelido a consumar una renuncia imposible: la de la búsqueda de su propia plenitud que, en el esquema evagriano, consiste en el conocimiento de los seres y de la ciencia de la Trinidad. Por eso la ofuscación que provoca la acedia frente a sí misma se sostiene también en la certeza de poseer los frutos del conocimiento de la verdad (Contro, 129), lo que evoca inmediatamente la ambigüedad de la "caída" heideggeriana por la que se vive en la ilusión de saberlo todo, ilusión que obstruye las genuinas posibilidades de ser (Ser 196). Renunciando y huyendo de sí, el acedioso, como el Dasein caído, viene ineluctablemente tras de sí. De esto modo se "enreda en sí mismo" y se "despeña", no 
precipitándose a otra cosa que a sí mismo. Agamben expresa esta misma idea en los siguientes términos: "Que el acedioso se retraiga de su fin divino no significa, de hecho, que logre olvidarlo o que cese en realidad de desearlo" (27).

El Dasein así caído existe impropiamente porque, en tanto ser-con sometido a la dictadura del "Uno", se rinde por así decir ante la tentación de medianía con que tal dictador lo seduce. Esta noción de "medianía" es introducida por Heidegger para explicar precisamente la sugestión incoercible de ese "Uno" (sujeto de la vida cotidiana) para vivir como se vive, pensar como se piensa, rezar como se reza, y así existir impropiamente. Una instigación de naturaleza análoga inspira muchas de las sugestiones de la acedia consignadas por Evagrio en el Antirrhéticos. El demonio de la acedia, en efecto, apela a pensamientos que nivelan todas las posibilidades de ser, como paso previo al abandono de una vida excepcional. La "medianía", indica Heidegger, "vela sobre todo conato de excepción" (Heidegger, Ser, 151). De este modo el demonio evagriano sugerirá al monje abandonar la lectura y el estudio soplando al oído pensamientos como el que sigue: "Un cierto santo anciano conocía solo doce salmos y era grato a Dios" (Contro, 130). O impulsa a abandonar la vida monástica aduciendo que "Un hombre puede obtener pureza e integridad también sin vida monástica" (Contro, 138) o que "El demonio de la acedia es muy potente y yo no estoy en grado de sostener el asalto de los pensamientos por él suscitados contra mí" (Contro, 130) y, además, "la divinidad puede ser adorada en todas partes" (Traité, 525). André Louf recrea las preguntas que el monje se realiza en semejante situación: “¿Es que Dios puede exigir realmente esta «pureza monástica» que alguien hizo brillar ante sus cándidos ojos de novicio? ¿No se contentará acaso con la fe humilde de los que viven en el mundo?" (345-46). Bunge agrupa todo este conjunto de sugestiones propias de la acedia bajo la categoría de "minimalismo" (Akèdia, 85). Se trata, como vemos, de una tentación de "medianía". La vida monástica, su rutina y su disciplina, son ciertamente excepcionales. Contra ello existe una instancia, personificada para Evagrio en un demonio, que busca obliterar la excepcionalidad, quitar - en palabras de Heidegger- fuerza al misterio (151).

Este paralelismo entre la medianía a que impulsa el "Uno" y el minimalismo de las sugestiones de la acedia, nos mueve a encontrar en dicha noción heideggeriana un criterio hermenéutico esclarecedor para interpretar muchas de las sugerencias interiores de la acedia registradas minuciosamente por Evagrio. Por lo demás, siendo el "Uno" el perpetrador de la caída y mostrándose esta fenoménicamente equivalente a la acedia, no resulta extraño encontrar en el dinamismo del padecimiento evagriano la acción de una instancia semejante o idéntica al "Uno" de Heidegger. En efecto, el monje que padece acedia se ve literalmente invadido por pensamientos o palabras que, buscando que abandone su vida excepcional -0 como escribe significativamente Evagrio "que abandone el estadio" (Traité, 527)-lo invitan a considerar lo que "uno" en tanto monje podría hacer en lugar de permanecer en la celda: un monje, en efecto, visita enfermos, visita a sus hermanos, se ejercita en la caridad, se somete a penitencias razonables y no 
excesivas. En otros casos tales pensamientos pueden aducir que la vida monástica es demasiando dura y que difícilmente un hombre puede soportarla. Este hombre no identificado es el mismo que referíamos más arriba como aquel que puede obtener pureza e integridad también sin vida monástica. Es un hombre impersonal y a él se puede, como al "Uno" heideggeriano, acudir en cualquier momento para hacerlo cargo de todo. Apelar, por ejemplo, al caso del santo monje que solo conocía doce salmos o sostener que en otros lugares se sirve mejor a Dios es proporcionarse, acudiendo al "Uno", lo que Heidegger llama un "alivianamiento" haciendo las cosas en forma fácil $(\operatorname{Ser}, 152)$.

El "Uno" permite, en fin, un encubrimiento igualmente significativo y fundamental -como veremos ahora- en la constitución tanto de la caída heideggeriana cuanto de la acedia evagriana: el del propio estar vuelto hacia la muerte.

3. EL $\alpha \kappa \eta ́ \delta \varepsilon \tau \omega \varsigma$ GRIEGO Y EL COTIDIANO ESTAR VUELTO HACIA LA MUERTE DEL DASEIN

Como ya hemos indicado, Evagrio apela significativamente a un término griego a la sazón poco determinado, como el de acedia, para designar una singular experiencia de atonía, dispersión y disgusto generalizado que padecen los monjes. En la literatura cristiana anterior a nuestro autor el término es mencionado por San Atanasio, por San Gregorio Nacianceno y por Orígenes (Guillaumont, Traité, 85). Se adivina en dichas menciones el sentido clásico del término y se esclarecen las posteriores vinculaciones evagrianas de la acedia con la cobardía y la somnolencia, pues Orígenes, el principal referente doctrinal de Evagrio, la sitúa entre estas dos últimas a la hora de hablar de las muchas tentaciones que padeció el Señor Jesucristo durante los 40 días de ayuno en el desierto (Orígenes, 503).

El origen del término acedia se encuentra en la locución griega $\alpha \kappa \eta ́ \delta \varepsilon \tau \omega \varsigma$ que es, como sugiere la alfa inicial, el privativo de $\kappa \eta \delta \varepsilon ́ \omega$, cuya acepción general es cuidado, solicitud, preocuparse por algo o alguien. Su significado primario es, por lo tanto, falta de cuidado o incuria. En este sentido es usado, por ejemplo, por Platón en Leyes ("Pero si alguien no cuida ( $\alpha \kappa \dot{\eta} \delta \eta \varsigma)$ a sus hijos,..." [XI, 913 c.]). No obstante, el término es usado también, entre los griegos, con un sentido más preciso y de mayor implicancia filosófica. Él designa una falta especial de cuidado, una despreocupación o incuria singularísimas que los griegos creen menester especificar, pues no se trata de una despreocupación cualquiera. La incuria que designa este término tiene que ver con la existencia misma y con cómo esta es afrontada y vivida. $\alpha \kappa \eta ́ \delta \varepsilon \tau \omega \varsigma$ es, en fin, falta de interés o de cuidado por la sepultura, renuncia al duelo, ausencia de ritos funerarios, despreocupación ante la muerte. En este sentido es usada, por ejemplo, por Homero: "No me ofrezcas asiento, criatura de Zeus, mientras Héctor yace en las tiendas insepulto ( $\alpha \kappa \dot{\gamma} \delta \dot{\eta} \varsigma)$..." (llíada XXIV, 553-554). Tal despreocupación resulta para los griegos de una inusitada gravedad. Ella contradice una ley no escrita e 
inquebrantable que no es de hoy ni de ayer sino de siempre (Sófocles, Antígona, 4546), y expresa una condición existencial inquietante. Como indica Forthomme, los griegos adivinan en esta despreocupación, expresada en la incapacidad de guardar duelo, una hesitación dramática acerca de la propia identidad, una angustia manifiesta en cuanto al propio origen, naturaleza, ambiciones y destino (Émergence, 16). La utilización, recogida por Forthomme, que hace Empédocles de nuestro término expresa claramente esta idea. Él mismo designa para el presocrático un espíritu despreocupado de sí mismo. Se trata, en suma, de una despreocupación -la que se refiere a los difuntos- que manifiesta una incuria del hombre respecto de sí mismo, incuria por la que se oblitera la dimensión especular de la muerte. El despreocupado griego es aquel que no solo no sabe quién es sino que ha perdido el interés por saberlo. Como indica Peretó Rivas, "la ausencia del duelo es mucho más que el descuido de un debido acto piadoso. Ella esconde algo que transciende el hecho concreto y físico de sepultar a un muerto. Es la revelación del profundo descuido de sí mismo manifestado en la ligereza o superficialidad en el tratamiento de la propia vida" (Entre pecado capital, 2).

Este sentido originario del término es recogido ciertamente por Evagrio y es el que de alguna manera unifica las diversas y contradictorias manifestaciones que tiene para él la acedia. Un eco explícito de aquel sentido lo encontramos en dos de los remedios que propone ante la acedia, a saber, la consideración de la propia muerte (Traité, 567) y el cuidado de sí (Képhalaia, 239). Por lo demás, la acedia resulta la tentación y la prueba suprema de una vida, la anacorética, cuya esencia es -como veremos enseguida- el "cuidado de la muerte", según escribe Evagrio.

Pues bien, establecido el paralelismo fenoménico entre la "caída" heideggeriana y la acedia evagriana no sorprende encontrar en las consideraciones del metafísico alemán acerca del modo cotidiano que tiene el Dasein de concebir la muerte, nuevas convergencias temáticas y conceptuales con el significado originario del vocablo acedia recogido por el monje del Ponto. Heidegger utiliza, por ejemplo, el término "ocupación" o, en la traducción de Gaos, "cura", para referirse a los ritos funerarios y exequiales de que es objeto el difunto (Ser, 259; El ser, 273). El "cuidado del sepulcro", como traduce Gaos (273), es para Heidegger un tipo especial de cuidado que, sin embargo, se ve desvirtuado por la existencia cotidiana que sitúa la muerte de los otros en el cuadro de lo que comparece cotidianamente dándole así un marco de sentido que garantice que la muerte es un evento habitual del que, por lo pronto, se está a salvo. Se oculta así su carácter de posibilidad irrespectiva e insuperable. La existencia cotidiana impropia fruto de la caída -la que se nos ha mostrado fenoménicamente semejante a la acedia evagriana- se configura como tal a partir de una huida frente a la muerte como posibilidad más propia. El encubridor esquivamiento de la muerte -señala literalmente Heidegger- domina tenazmente -encarnizadamente en la traducción de Gaos- la cotidianidad del Dasein caído, de tal manera que configura comportamientos esquivos frente al moribundo -intentando persuadirlo que se librará de la muerte- y frente al 
difunto mismo cuya muerte es vista como una inconveniencia social (Ser, 273-74; El ser, 291). La muerte de los otros tiene una proyección especular de la que el Dasein caído huye.

Heidegger precisa más aún el modo sutil que tiene la cotidianidad de encubrir el morir en tanto posibilidad propia. Estas precisiones enriquecen y profundizan el análisis de lo que el $\alpha \kappa \eta ́ \delta \varepsilon \tau \omega \varsigma$ griego ya había esbozado cuando nos indicaba que la actitud descuidada frente a los muertos revela una huida frente a la imagen especular que la muerte de otros devuelve. La existencia cotidiana de Heidegger, en efecto, concede una certeza ambigua de la propia muerte, pero solo para mitigar su condición de posibilidad: ciertamente uno también se muere alguna vez, ciertamente la muerte vendrá, pero por el momento todavía no, se dice el Dasein caído (Ser, 275). La función de tal certeza -que Heidegger llama "inadecuada" porque "mantiene en el encubrimiento aquello de lo que está cierta" (Ser, 276)- es garantizar la obliteración de la proyección especular de la muerte, y esto entendiéndola como un evento que, ciertamente, "tiene lugar en el mundo circundante", pero que por el momento no toca al Dasein propio. Esta certeza inadecuada es la que configura la consideración superficial y carente de un auténtico y reflexivo cuidado, de "los casos de muerte que acontecen" asegurando así la tranquilidad de la vida cotidiana mediante la puesta al margen de la existencia de su posibilidad más propia e insuperable.

Evagrio, por su parte, propone frente a un tal descuido, que tan sutilmente se instala y configura la propia existencia, el pensamiento de la propia muerte. Este pensamiento no es una mera concesión tranquilizante frente a un hecho inevitable. La vida monástica misma es, en esencia, "ejercicio de la muerte" según una tradición recogida y consolidada por Evagrio y legada por él mismo al monacato posterior. Bunge, al comentar el $\alpha \varepsilon \varphi \alpha ́ \lambda \alpha \iota \alpha$ o capítulo breve del Tratado Práctico que trata acerca de este remedio de la acedia, indica que el apotegma que Evagrio evoca allí recoge palabras de Macario el Grande, su maestro y uno de los grandes referentes del movimiento monástico. El hombre, decía Macario, debe vivir valientemente delante de la muerte, la que tal vez lo sorprenda mañana (Bunge, Trattato, 134). Macario, por su parte, no hace otra cosa que recoger la enseñanza del mismo San Antonio Abad, fundador del movimiento eremítico, quien exhortaba a sus discípulos de idéntica manera: "Cada día, al despertar, pensemos que no subsistiremos hasta la tarde, e igualmente, cuando estemos por acostarnos, pensemos que no despertaremos" (Guillaumont, Traité, 568-569. Trad. mía). La muerte es así posibilidad propia e inminente y su cuidado define la vida monástica. No es ella -en el pensamiento del monacato y de Evagrio mismo- un acontecimiento que sucede en el mundo circundante y que por el momento no toca al propio ser. Por el contrario, ella es "siempre posible" (Bunge, Tratatto, 134) y el monje debe vivir diariamente con esa certeza. Este "ejercicio de la muerte", esencia de la anacoresis, puede entenderse, en efecto, como un "correr al encuentro" de la muerte, como traduce Gaos (301). Esta es para los monjes la posibilidad suprema de la existencia, y la vuelta hacia ella es lo que 
los define como anacoretas. La acedia es, por su parte, la tentación suprema de una vida que es ejercicio o cuidado de la muerte. Por tanto, la acedia constituye una obliteración del ejercicio de la muerte que se supera recuperando el registro existencial de la misma. "Todos los pensamientos de acedia pierden significado de frente a la muerte siempre posible" (Bunge, Tratatto, 134. Trad. mía). Paralelamente el "correr hacia el encuentro" de esta posibilidad suprema es para el Dasein, como indica Heidegger, revelarse su estado de perdido en el uno, es decir, la impropiedad de su existencia, su caída entre los entes que no son él (El ser, 302).

Resulta muy significativa la expresión que, recogiendo la tradición de los Padres, utiliza Evagrio para referirse a esta esencia de la vida monástica que venimos mentando: $\mu \varepsilon \lambda \dot{\varepsilon} \tau \eta v$ $\theta \alpha v \alpha \dot{\tau}$ ov. Siguiendo las traducciones francesa e italiana pertenecientes, respectivamente, a Guillaumont y a Bunge, hemos hablado de "ejercicio de la muerte". Pero el término $\mu \varepsilon \lambda \dot{z} \tau \eta v$ admite también una traducción reveladora: cuidado, preocupación, atención, solicitud. La acepción general del término "cuidado" se corresponde para los griegos con una palabra, y el tipo especial de cuidado de que son objeto los difuntos con otra, de acuerdo con lo que hemos indicado respecto del origen del término acedia. Pero aquí se está hablando justamente de ejercicio o cuidado de la muerte $(\theta \alpha v \alpha ́ \tau o v)$. La utilización de un término distinto por parte de Evagrio podría explicarse por la proyección práctica del término $\mu \varepsilon \lambda \dot{\varepsilon} \tau \eta v$ que también es ejercicio, práctica. Asimismo $\kappa \eta \delta \varepsilon ́ \omega$ designa una acción específica de cuidado (la de los difuntos) y aquí Evagrio utiliza la acepción general de cuidado para referirla inmediatamente a la muerte. Aunque el cuidado de los muertos revele el cuidado de la muerte en general (y se proyecte así en un significado de implicancia antropológica, psicológica, metafísica), la acción específica del cuidado de los difuntos se designa con un término particular distinto al que se usará para hablar genéricamente del cuidado de algo (un algo que en este caso es la muerte). Con todo, lo significativo aquí es que Evagrio utilice la expresión "cuidado-ejercicio de la muerte" al referirse a la esencia de un estado de vida, el anacorético, que en rigor no busca sino vivir en su real dimensión -y esto lo singulariza- el hecho de ser, para usar la terminología heideggeriana, seres para la muerte. Una muerte que ciertamente tiene en Evagrio un significado que no aparece en Heidegger.

Todo ello sugiere, en fin, que la acedia, en tanto descuido frente a la muerte y frente a sí mismo, es la tentación específica y propia de la vida monástica y de la existencia humana en general. Una tentación que evoca aquella que padece el Dasein en cuanto tal y por la que vive su existencia cotidiana dándose la espalda a sí mismo, esto para Heidegger es existir dando la espalda a la muerte como la posibilidad más propia.

\section{CONCLUSIÓN}

La complejidad y riqueza de la noción de acedia ha motivado y motiva los más diversos estudios. La dificultad en encontrar una definición precisa y unívoca de ella 
estriba en que la realidad que se propone designar es, en efecto, compleja, contradictoria, multicausal. Psicólogos, religiosos, literatos, historiadores, filósofos hacen de la acedia objeto de su investigación, desde orientaciones tan diversas como la psicoanalítica, la fenomenológica, la tomista, la evagriana. No resulta extraño entonces que, constituyendo un hecho insistente que siempre admite nuevas perspectivas, también reaparezca en la consideración de los filósofos con otras denominaciones. El dandismo, la melancolía, el vacío existencial constituyen otros tantos conceptos que -como ha demostrado, entre otros, Bernard Forthomme- designan, en parte, realidades que los antiguos ponían bajo el término acedia. La existencia impropia de Heidegger, resultado de la caída, parece asimismo nominar en muchos sentidos una realidad semejante a la que define a la acedia. Esta convergencia, registrada ya en lo que se refiere a la noción medieval y principalmente tomista de acedia, alcanza en el paralelismo con la noción evagriana horizontes insospechados. Hemos visto, en efecto, que la equivalencia entre ambos estados permite una complementariedad hermenéutica que puede enriquecer notoriamente el estudio de la acedia.

Ciertamente las confluencias fenomenológicas no son suficientes para concluir que Heidegger se está refiriendo, con su conceptualización de la existencia impropia, al mismo hecho a que se refiere Evagrio con la noción de acedia. Ha sido necesario indagar en el significado de tales manifestaciones y ver allí la posible identidad que insinúa la confluencia fenomenológica. Y, en efecto, la acedia y la caída (fenoménicamente parangonables) resultan condiciones humanas equiparables, pues la configuración fenomenológica de ambas se explica por la huida de sí que implica el no cuidado de la muerte. Y ya hemos visto que es la huida de la muerte como la posibilidad más propia, irrespectiva e insuperable de la condición humana la que funda ambos estados. Esta huida, ineluctable para el Dasein heideggeriano, lo es también para el hombre evagriano. La acedia ataca al medio del día, al centro de la existencia, y es por ello el más peligroso, el más constante de todos los enemigos (es de notar que Evagrio solo para el ataque del demonio de la acedia establece un horario diario definido, que no para el resto de los siete demonios). Ella hace vivir al hombre - y al monje que se entrega a una vida de combate contra ella- de espaldas a su muerte. Por ello la vida monástica misma la tiene como antagonista principal en tanto ella se define, según hemos visto, como cuidado de la muerte. En este sentido dicha vida puede ser entendida abriendo un nuevo camino de indagación, como un modo propio o auténtico de existir pues consiste en asumir cada día la propia condición mortal o, como traduce Gaos a Heidegger, en "correr al encuentro de la muerte".

Universidad Nacional de Cuyo* Centro de Estudios Filosóficos Medievales, Facultad de Filosofia y Letras Almirante Brown 3390, Loteo Los Olmos casa 32, Vistalba, Luján de Cuyo, Mendoza (Argentina) santiagohernanvazquez@gmail.com 


\section{OBRAS CITADAS}

Agamben, Giorgio. Estancias. Madrid: Biblioteca de Filosofia. Editora Nacional, 2002.

Aho, Kevin. "Recovering Play: On the Relationship Between Leisure and Authenticity in Heidegger's Thought", Janus Head 10/1(2007): 217-238.

Balzac, H. Un prince de la Bohème. Québec, 2010. La Bibliothèque électronique du Québec. Édition de référence: Paris, Alexandre Houssiaux, Éditeur, 1853. Web. 24 Jul. 2014.

Basave Fernández, Agustín. "Temas y problemas de la antroposofía metafísica", Diánoia, 1 (1) 1955: 350-371.

Baudelaire, Charles. Journaux intime. Pusées, mon Coeur mis a nu. Paris: Les Éditions G. Crés et Cie, 1920.

Benjamin, Walter. El origen del Trauerspiel alemán. Web. Consultado: 29 Jul. 2014. Disponible en: https://direccionmultiple.files.wordpress.com/2012/05/traverspiel.pdf Bourget, Paul. Le démon de midi. París: Librairie Plon, 1914.

Bouvier, David. "La fascination du cadavre dans la poésie homérique". Antigone et le devoir de sépulture. Ed. Muriel Gilbert. Genève: Labor et Fides, 2005: 70-84.

Bunge, Gabriel. Akèdia. La doctrine spirituelle d'Èvagre le Pontique sur l'acedie. Bellefontaine: Abbaye de Bellefontaine, 1991.

— (Ed. y trad.) Trattato Pratico. Por Evagrio Póntico. Magnano: Qiqajon, 2008.

Cioran, Emil. Breviario de Podredumbre. En línea, consultado: 21 Jul. 2014 http://crimideia.com.br/blog/wp-content/uploads/2010/02/emil-cioranbreviario-de-podredumbre28194929.pdf

_ De lágrimas y santos. En línea, consultado: 21 Jul. 2014: http://espanol.freeebooks.net/ebook/De-lagrimas-y-de-Santos/pdf/view

_ La tentación de existir. En línea, consultado: 21 Jul. 2014. Disponible en: http:/crimideia.com.br/blog/wp-content/uploads/2010/02/emil-cioran-latentacion-de-existir28197029.pdf

Evagrio Póntico. Contro i pensieri malvagi. Antirrhetikos. Ed. y Trad. Valerio Lazzeri. Magnano: Qiqajon, 2005.

_ Gli otto spiriti della malvagità. Ed. y Trad. Francesca Moscatelli. Milano: San Paolo, 1996.

— Képhalaia gnóstica. Ed. y Trad. Antoine. Guillaumont. Patrologia Orientalis, T. XXVIII, fascicule 1. Parçis: Firmin-Didot, 1958.

— Traité pratique ou le moine. Tomo II. Ed. y Trad. Antoine Guillaumont y Claire Guillaumont. París: Cerf, 1971.

Forthomme, Bernard. De l'acédie monastique à l'anxio-dépression: histoire philosophique de la transformation d'un vice en pathologie. París: Synthélabo, 2000.

"Émergence et résurgence de l'acédie". Tristesse, acédie et médecine des âmes dans la tradition monastique et cartusienne: anthologie de textes rares et inédits, XIIIe-XXe siècle. Ed. Nathalie Nabert. París: Beauchesnes, 2005. 15-35. 
Gibbs, Paul. Heidegger's Contribution to the Understanding of Work-Based Studies. Chipre: Springer, 2011.

Guillaumont, Antoine, ed. y trad. Traité Pratique ou le moine. Tomo I. Por Evagrio Póntico. París: Cerf, 1971.

_ Un philosophe au désert. Évagre le Pontique. París: Vrin, 2009.

Heidegger. Martin. El Ser y el Tiempo. Trad. José Gaos. México: Fondo de Cultura Económica, 1988.

— Ser y tiempo. Trad. Jorge Eduardo Rivera. Santiago de Chile: Editorial Universitaria, 1997.

Kierkegaard, Søren. Diario I (1834-1849). Trad. Cornelio Fabro. Brescia: Morcelliana, 1962.

Louf, André. "L'acédie chez Évagre le Pontique", Concilium, 99 (1974): 113-117.

Mounier, Emmanuel. L'affrontement chrétien. París: Éditions de la Baconnière, 1948.

Nabert, Nathalie. "Introduction. Un concept oublié". Tristesse, acédie et médecine des âmes dans la tradition monastique et cartusienne : anthologie de textes rares et inédits, XIIIe-XXe siècle. Ed. Nathalie Nabert. Paris: Beauchesnes, 2005. 9-12.

Nietzsche, Friedrich. Obras completas VIII. Trad. Eduardo Ovejero y Maury. Buenos Aires: M. Aguilar, 1947.

Orígenes. Homélie sur Luc. Trad. y ed. Henri Crouzel. París: Cerf, 1962.

Palleschi, Francesco. "L'acedie dans l'oeuvre d'un prémontré devenu chartreux au XIIe siècle. Adam Scot et le "Liber De quadripertito exercitio cellae". Tristesse, acédie et médecine des âmes dans la tradition monastique et cartusienne: anthologie de textes rares et inédits, XIIIe-XXe siècle. Ed. Nathalie Nabert. París: Beauchesnes, 2005: 15-83.

Peretó Rivas, Rubén. "Acedia y depresión. Entre pecado capital y desorden psiquiátrico", IV Jornadas Nacionales de Filosofia Medieval, Academia Nacional de Ciencias, Buenos Aires, 2010.

__ "El itinerario medieval de la acedia". Intus-legere: historia, 4 (1) 2010: 33-48.

_ "Acedia y depresión. Aportes para una reconstrucción histórica". Eä, 3/1 (2011): 1-20.

_ "Las mutaciones de la acedia. De la Patrística al Medioevo". Studium: filosofia y teología 14 (11) (2011): 159-173.

_ "Evagrio Póntico y la exclaustración de la acedia". Carthaginensia: Revista de estudios e investigación, 28 (53) 2012: 23-35.

__ “Moritur in solitudine': la acedia en la vida de Hugo de Miramar". Stylos, 22. 2013: 174-186.

Pieper, Josef. Antología. Barcelona: Herder, 1984.

—_ El ocio y la vida intelectual. Madrid: Rialp, 1970.

Las virtudes fundamentales. Madrid: Rialp, 2008.

— Una teoría de la fiesta. Madrid: Rialp, 1974. 
Iranzo, Iván. "Melancolía y sacrificio en la ciencia ficción contemporánea". Formats. Revista de comunicación audiovisual, 5. 2009. En línea, consultado: 30 jul. 2014. http://www.upf.edu/materials/depeca/formats/pdf_art_dos_esp4.pdf

Platón. Leyes. Ed. Édouard Des Places. París: Les Belles Lettres, 1956.

Rovaletti, María Lucrecia y Pallares, Martín. "La acedia como forma de malestar en la sociedad actual". Revista Latinoamericana de Psicopatología Fundamental, 17/1(2014): 51-68.

Schumacher, Bernard. "El hombre de ocio: parásito o transformador del mundo". Sapientia, 59/216 (2004): 523-541.

Sófocles. Tragedias. Trad. A. Alamillo. Madrid: Biblioteca Gredos, 2006.

Theunissen, Michael. Anteproyecto de modernidad: antigua melancolía y acedia de la Edad Media. Valencia: Colección Náyade, 2005.

Tomás de Aquino. Suma de Teología II-II. Trad. Ovidio Calle Campo. Madrid: BAC, 1998.

Vázquez, S. "Acedia y depresión. Manifestaciones fenomenológicas y dinamismo psicológico". Seminario de Filosofia Medieval, Centro de Estudios Filosóficos Medievales de la Universidad Nacional de Cuyo, Mendoza, 2013.

Van den Broek, Roelof. Pseudo-Cyril of Jerusalem on the life and the Passion of Christ. A Coptic Apocryphon. Leiden: Brill, 2013.

Vernant, Jean-Pierre. L'individu, la mort, l'amour. Soi-même et l'autre en Grèce ancienne. París: Gallimard, 1989.

Wenzel, Siegfried. "Acedia 700-1200”. Traditio, 22 (1966): 73-102.

- The Sin of Sloth. Acedia in Medieval Thought and Literature. Chapell Hill: The University of North Caroline Press, 1967. 